\title{
Aesthetic View of Farmer's Art from the Perspective of Wuqiang New Year Paintings
}

\author{
Jinmin Liu ${ }^{1}$ \\ School of Fine Arts \\ Shijiazhuang University \\ Shijiazhuang, Hebei, China, 050035
}

\author{
Sheng $\mathrm{Bi}^{2}$ \\ School of Foreign Languages \\ Shijiazhuang University \\ Shijiazhuang, Hebei, China, 050035
}

\begin{abstract}
As one wonderful flower of farmers' art with a rich local smell, Wuqiang New Year paintings are pure art from farmers' bones. Their simple and unadorned modeling, stable and harmonious composition, and strong color application all condense farmers' wisdom and aesthetic conception of thousands of years.
\end{abstract}

Keywords-Wuqiang New Year paintings; aesthetic view; modeling; composition; color

\section{INTRODUCTION}

New Year paintings are local folk art developed under the influence of primitive cultivation methods, traditional ideas, and ancient folk beliefs, known as the "picture dictionary of folk life". Recording the public's lifestyle, customs, thoughts and feelings, as well as expressing people's pursuit of ideal life, New Year paintings are one art form with distinct style - an indispensable part of farmers' lives and one favorite plastic art of the common people. Wuqiang New Year paintings are outstandingly representative of northern rural New Year paintings. Wuqiang is famous for its reputation as 'the home of New Year paintings'. Their New Year paintings, from aspects of subject and contents, modeling characteristics and art style, all are rated as first class. Contemporary writer Feng Jicai highly praises them - "which New Year painting is better, Wuqiang is the first."

Wuqiang people survive generation to generation in the rural environment of "loess on all sides", and form their own aesthetic taste and aesthetic view. To the most extent, they record cultural tradition and customs of northern farmers, and their aesthetic view is revealed and inherited vividly in the records, which is also the artistic value. This paper makes us truly appreciate the aesthetic taste and aesthetical standards of simple farmers' art through analysis of the unique modeling, composition and color of Wuqiang New Year paintings.

\section{SIMPLE AND UNADORNED MODELING}

Since ancient times, drought and flood disasters have been frequent in Wuqiang; people often live in an abyss of misery. They dig rivers and control water, dig wells and fight against drought and cultivating plants from generation to generation. There is no mountain or sea; living conditions are congenitally deficient. Long-term poverty and backwardness, and the constraint of feudal thought, forms Wuqiang peoples' characters - "simple and dull, diligent and pragmatic, planned and frugal, tough and brave... [1]". Specific geographical environment forms the Wuqiang people's character: honest and pragmatic, industrious and simple, plain. Therefore, New Year paintings drawn by local farmers must be a popular and demotic art form; a product under deep influence of geographical environment, material culture and life contents, as well as a way of revealing the truth of local farmers' inner feelings and concept. Local farmers' character traits, such as simple and unadorned, sincere and bold, and unconstrained, form the simple and immature modeling characteristics of Wuqiang New Year paintings and also reflect aesthetic standards of northern farmers. This can be summarized into two points:

\section{A. Resemblance in Spirit rather than Form}

The essence of Chinese painting is "resemblance in sprit". Literati painters and court painters through the ages all advocate "vivid portrayal", "advocating sprit", "writing sprit from shape", "the beauty is between resemblance and un-resemblance" - romantic charm is taken as guiding the ideas of painting, which are artistic effects deliberately pursued by painters. However, resemblance in spirit rather than in the form of Wuqiang New Year paintings is not deliberately pursued by folk artisans, but is naturally revealed through artistic characteristics in their creation process, as well as the potentially unconscious expression of focus on spirit and romantic charm from Chinese bones.

Creators of early New Year paintings were not professionally educated, just ordinary people, mainly folk artisans, farmers and handicraftsmen. Even in New Year painting sample manuscripts, designed by professional painters, the painting will be carried with simple and unadorned characteristics through hand printing. Their cut blocks for paintings adopt simple lines and the line carving is drastic, rough and unrestrained, tall and straight and scattered, highly generalized - the overall modeling is simple and immature. For example, Liu Hai's finger modeling, side-by-side short fingers in "Liu Hai Plays with Jin Chan" are one of the classical unadorned characteristics of farmers' art. In addition, approximate parallelogram eyes 
in Gate God and square eyeballs, fish hook noses and the neat beards of some early figures on cut boards all adopt straight knife curving without decoration - the lines are powerful and rough. They also understand that the modeling is inaccurate. However, the modeling does not affect the mental outlook of the modeling which he wants to depict anymore, but strengthens its unadorned beauty, and makes its image penetrating with extraordinary romantic charm. This fully shows the modeling idea of farmers' art - a resemblance in spirit rather than form. It is the promotion and implementation of Lao Zi's "great wisdom appears stupid" in artistic creation field, and the source of the aesthetic conception of taking simplicity as beauty.

\section{B. With Exaggeration and Deformation, Highlighting Key Points}

With farmers' art, "each painting has a meaning". Wuqiang New Year paintings always exaggerate their theme characteristics through modeling. When depicting images and highlighting required "meaning", but not simply imitation, they mainly show inner sprit and vitality. That just corresponds to the requirements of Chinese philosophy and aesthetic ideology on modeling - through exaggeration and deformation, highlighting key points and expressing truth, the goodness and beauty of things, and extracting essence and sprit. That is the artistic value of Wuqiang New Year paintings. Of course, this is only one coincidence. In the early stage of New Year paintings, illiterate famers didn't understand philosophy and aesthetics, and the exaggeration of expression mainly comes from the unconscious psychology and emotions of the farmers' hearts.

'Gate God' is one image generated in the conditions of extremely low productivity and extremely undeveloped science; it is used to bring luck and help avoid evil spirits, and remove disasters and difficulties. In order to exaggerate the force and bravery of 'Gate God' and to reach the deterrent effect of expelling and avoiding evil spirits, figure modeling especially exaggerates the head and makes the head account for one third of the whole body height. The models have a sturdy body but no neck, and are horizontal but not vertical. The exaggerated head highlights the figure's face; a broad face with glaring eyes shows uprightness and stateliness. The lion modeling in Wuqiang New Year paintings is simple and immature, like the lion of a stone carving; the lion possesses the dignified feeling of sculpture modeling. It also exaggerates the head, known as the saying "nine jin head in ten jin lion", and highlights the eyes; the modeling processing technique of god tiger and that of lion are the same. There are so many of these examples they cannot be cited one by one. Wuqiang New Year paintings express vigorous and strong vitality of farmers' art through this exaggeration technique. The integral tension and momentum is beyond the reach of court art and literati art. Their steady and vigorous modeling expresses simplicity, roughness, vitality and thriving, stretching and unrestraint; and makes the whole New Year paintings more charming. The reason why the modeling characteristics of Wuqiang New Year paintings have not changed through many years of development is that they meet the aesthetic needs of local farmers. Moreover, local farmers' pureness and simplicity can be seen from New Year paintings art.

\section{Pursuing Completeness and Happiness}

Chinese traditional aesthetics emphasize the integral consciousness of unity between subjectivity and objectivity, and "pursue completeness and happiness". It is believed that everything is harmonious as one, has unified integrity and follows one essence law. Therefore, ancient Wuqiang New Year paintings artists always devote themselves to the creation of "integrity is beauty", which also reflects labor people who pray for completeness and entirety, and pursue perfect utility psychology. Figure modeling especially shows this thought. Figure modeling is ordinarily required to be whole and complete; the front side of the figure is adopted most, facing the audience, and the incomplete image is avoided. Farmers taboo side-facing figures or animals with one eye, as well as the phenomenon of lacking arms and legs when they select New Year paintings; in their view, these paintings are ominous.[1] Therefore, the figure face is either front facing or one third face. In a word, five sense organs must be complete and avoid a half face, to meet the aesthetic requirements of most farmers. Typically, all figures are well figured with arms and legs in "Men Busy at Ten Farming Activities", which fully reflect the farmers' psychology of pursuing perfection.

It can be seen that modeling of Wuqiang New Year paintings pursue perfection and do not stick to true natural depiction, but dare to break the routine. In order to meet their own aesthetic intention, they must: perform idealization processing and make the image rich in romantic, ideal and exaggerated characteristics, and pursue "truth" in conception. This demonstrates the simple and immature aesthetic view of farmers' art.

\section{Picture COMPOSITION OF COMPLETE DESIRE APPEAL}

If you carefully observe Wuqiang New Year paintings, you will find that both their composition and modeling are expressionistic, not naturalistic. Typical characteristics are full and complete, evenly symmetrical; it is not only beneficial for the printing process, but also one reflection of farmers' aesthetic idea. New Year paintings are designed fully by artists; they are given to the people as full, flourishing and lucky, with a sense of beauty. People's general psychological pursuit in agrarian society is abundant life; ample food and clothing is people's eternal pursuit and the most basic desire and appeal of life, which is the reason why we cannot see "emptiness and quietness" and the chunk blank effect of literati painting in New Year paintings. People don't want illusory and idealized things; they put greater emphasis on whether the things are real. Symmetric and balanced composition gives a sense of security and stability, of safety and peace, to meet the farmers' desired appeal of "peace and safety in all seasons". Farmers feel the compositions are beautiful from their hearts when they see them. And from that, an agreement in aesthetic taste is formed. 


\section{A. Pursuing Completeness and Perfection}

The composition mode of New Year paintings is closely related to Chinese traditional values and outlook on life; advocating completeness and perfection is one psychological orientation of traditional aesthetics. In Chinese concept, "perfection" is closely related to "completeness", not only "perfection and completeness" forms a word, but also "perfection" due to "completeness". For example, "many children and grandchildren", "full of brightness", "shine with happiness", and "a sty filled with pigs" are all 'perfect words' in Chinese, symbolizing that wonderful and abundant words all have the meaning of "completeness"[2]. Posting New Year paintings in spring festival is to expect flourish, luckiness, pleasures around, fullness, good harvests and thriving domestic animals. The composition of New Year paintings is destined to be full, which can meet the masses' thought desire and give them beauty. For example, in many farming and weaving paintings, various figures, animals and scenery break up space-time limitation: with size and spacing and alternate arrangement, complete picture and lively atmosphere, vividness but not disordered. In one ancient New Year painting of "Busy Farming Life", more than 20 farmers are working in the field: ploughing, sowing, weeding, harvesting and threshing. This large span of space-time reasonable figures arrangement vividly shows a pleasant busy farming life scene. One passage of interesting words in traditional opera libretto is engraved on the top of picture. The composition is complete, full and even. Similarly, there are "Men Busy at Ten Farming Activities" and "Women Bust at Ten Domestic and Weaving".

The thought of pursuing completeness is expressed vividly in the figure modeling of New Year paintings. Similarly, this simple and romantic innocent thought is expressed naturally and truly in composition. The most typical example is the "All Celestial and Earthly Gods". People's desires for long life, safe and abundant life, large family, many children and grandchildren, favorable weather, good harvests, wealth and fortune and booming business are attached to the belief and worship of gods. There are a great variety of gods in Wuqiang New Year paintings and the basic necessities are all involved. In the "All Celestial and Earthly Gods", celestial, earthly, human and ghosts, Confucianism, Buddhism and Taoism and other folk gods are formed in to one large group. They are in their proper place, enjoy world life and pursue the blessing of all gods. The whole painting gives a simple and innocent smell, which makes woodblock printing rich in decorative effect, and makes us feel the farmers' dullness and simplicity. The farmers' longing for beautiful life is placed on the gods, to meet completeness in psychology and their utility needs; the picture also shows farmers' unadorned aesthetic view of pursuing completeness and perfection.

\section{B. Harmony and Balance}

As one basic essence of Chinese Ethnic People, "Harmony" and "Moderation" makes the Chinese pay more attention to the realization and maintenance of a harmonious situation. This relationship, pursuing harmony, forms the static, integral, and harmonious concept of Chinese Ethnic People, which is reflected in various fields such as human communication, religious legislation, calligraphy and paintings. Composition harmony shown in Wuqiang New Year paintings reflects this thought. Outward manifestation of New Year paintings and the contents of ideological and philosophical cultural ideas are always consistent. Single Wuqiang New Year painting often focuses on harmonious and balanced composition, for example, in gods painting, principal and subordinate is orderly and the situation is stable. In order to highlight the theme, the principal figure is prominently centered, and its shape is very big; other subordinate shapes are left-right symmetric by size level, which gives people a dignified and stable sense, such as "The God of Wealth". Besides, screen layouts of god paintings such as "The Kitchen God Palace", "Three Realms on Heaven and Earth" and "All Gods and Gate God" are complete, outlined shapes as one integrated mass, but detail comparison is variable and the composition as a whole is balanced and symmetrical. Also, although the "War in Tianjin" is not completely left-right symmetric and there is some change in the large symmetric situation, there is still a symmetric and balanced composition which makes the whole picture harmonious and unified. And there are "Fortune, Longevity and Fertility" and so on. In a word, a group of pictures adopts this composition form. Complete and balanced compositions of Wuqiang New Year paintings reflect farmers' simple thoughts and emotions and aesthetic requirements, which reach harmonious and unified artistic states.

\section{COlOR Pursuit of NeWness, Joyfulness AND GORGEOUSNESS}

Folk-art full of rich vitality and authentic local flavor has gorgeous and strong, rich and bright, simple and earthy color characteristics. Its color application has its own principles, pursuing decorative color but not real color; the tint method is mainly plain painting; pursuing a simple, lively, bright-colored and strong-contrast color effect. Its characteristics focus not only on harmony, but on emphasizing contrast and using high-purity colors such as bright red, yellow, blue, green, purple and black [3]. Color application must be affected by the traditional fives colors cultural concept, but I believes that farmer's own aesthetic ideas have played a decisive role in color application. I reduce it to the result of pursuing newness, joyfulness and gorgeousness.

\section{A. Expectation for "Newness"}

The reason why northern farmers prefer gorgeous colors is that in the past, farmers faced "four-side cob walls" and furniture in the house. Tools, clothes and other textiles in daily life were rarely changed due to low purchasing power; textiles at that time were cotton, and therefore faded easily, colors of these implements became old-fashioned and grey for a long time. Due to natural and man-made disaster, people lived very poorly and they became "depressed and dark". Furthermore, northern climate were dry, making the land poor and the species rare. Especially when celebrating 
the New Year Day in cold winter, people's expectation for "newness" was very strong. Bright colors and the strong visual perception of New Year paintings helped to meet farmers' desire for "newness". Therefore, posting one bright New Year painting when greeting the New Year Day brings a bit of light to the grey living environment and releases people's inner repression, as well as lighting up peoples' passion of pursuing a good life - they helped bring a festival atmosphere to the biggest festival in China and refreshed the people. This "newness" feeling still meets farmers' wide aesthetic taste and aesthetic requirements to this very day.

\section{B. Expression of "Joyfulness"}

Farmer artists don't understand that much color theory, they apply color completely from "unconsciousness" and completely rely on feelings and creative experience. They are not sticklers for the reappearance of natural scenes, but depict them at will, striving to realize hue with strong contrast, bright colors, vigorous and dense colors, flourish and liveliness, and auspiciousness and joyfulness. A chunk of pure color is applied boldly and the contrast of bright red and green is distinct. This joyous and lively color effect is suitable for decorating the joyous atmosphere of the Spring Festival, and can express farmers' inner "joyfulness". In order to express the inner feeling of "joyfulness", artists throughout all ages concentrated on studies and accumulated plenty of experience and make up ballads, and spread them up to now - such as "red next to yellow, glowing and flourishing", "red next to green, a drama", "red next to purple, damn ugly", etc. It can be seen that people taking bright red and bright green as dominant hue of New Year paintings is the result of multiple years of practical experience. People show special preference to red. Red is a joyous color in folk life and is widely used in folk activities such as weddings, birthday parties, births and festivals; green is a complementary color of red; the strong contrast can highlight the gorgeousness of red better. Throughout New Year paintings from ages, you will find that each picture has a large area of red and green for strengthening contrast. Farmers use bright red and bright green to express their inner "joyfulness", which is one of their most primitive aesthetic views.

\section{Connotation of "Gorgeousness"}

"Colors are bright and paper is white, New Year paintings come from Wuqiang". This shows that color brightness and liveliness are outstanding artistic characteristics of Wuqiang New Year paintings. For farmers who have grown up in the color environment of nature, their understanding for color mostly comes from the imitation of nature. Animals with gorgeous colors in the bodies are mostly highly toxic and extremely dangerous, such as vipers. The more gorgeous the color is, the more toxic the animal or plant is. Therefore, long-term life experience shows people that gorgeous colors always possess deterrent force. Farmers who lived with nature all year round have profound understanding. Posting New Year paintings originally was to meet the utility of exorcising evil spirits; the color application of Gate God takes example from nature, so brightly applied complementary colors widely strengthened visual impact with the warning effect of resisting attack of evil spirits. It is said that ghosts are afraid of blood, so large areas of red are applied to exorcise evil spirits. This primitive feeling for color becomes one source of folk color conception for thousand years of inheritance. It can be seen that color application of New Year paintings is a result guided by traditional culture concepts to some extent, it contains certain exorcise evil spirits, symbolic meanings, and rich social contents - it carries people's expectation for beautiful life.

\section{CONCLUSION}

Sincerity and innocence of farmer's emotion revealed by Wuqiang New Year paintings from modeling, composition and color is also the style of this art. Wuqiang New Year paintings are farmers' genuine aesthetic emotion, one "reality" from farmers' bones trained in real life. They are not genuine beauty, but show people's ideal, pursuit and wishes, and sincere appeal for auspicious contents such as: luck, fortune, longevity and happiness, trending luckiness and avoiding evil spirits, good harvests, favorable weather and a large family. They fully demonstrate the farmers' aesthetic taste and aesthetic view.

\section{REFERENCES}

[1] Qie Jianye: Artistic Style and Historical and Cultural Research of Wuqiang New Year Paintings. [M]. Baoding: Hebei University Press, 2007: 154 .

[2] Guo Xinsheng: Meaning, Shape and Color of Woodcut Picture of Chinese New Year [J]. Journal of Zhengzhou University of Light Industry (Social Science) 2005.6: 6.

[3] Mei Qing: On the Beauty Appealed by the Folk Lunar New Year's Painting [J]. Exploration and Free Views Theory Monthly, 2006, No. 4: 133 . 